\title{
1 Macroscopic effects of nano and microscopic phenomena in clayey soils and
}

2 clay rocks.

3

4

5

6

7

8

9

Pierre Delage

Ecole des Ponts ParisTech, Laboratoire Navier/CERMES, Marne la Vallée, France

Daniel Tessier

French Academy of Agriculture, Paris, France

Geomechanics for Energy and the Environment, 2020

https://doi.org/10.1016/j.gete.2019.100177

\begin{abstract}
Based on long term investigations of the microstructure of various geomaterials as different as sensitive low plastic clays from Eastern Canada, unsaturated compacted silt from the Paris area, highly plastic compressible deep marine clay from the Gulf of Guinea, compacted MX80 bentonite and the Callovo-Oxfordian claystone, considered as possible barriers in deep geological radioactive waste disposal, two fundamentals and distinct nano and micro mechanisms governing their macroscopic volume changes have been identified. In low plastic structured clays and dry compacted soils, in which an aggregate microstructure has been evidenced, the decrease in volume under mechanical compression result from the collapse of inter-aggregates pores in an ordered manner, from the larger to the smaller, with no effect on the intra-aggregate porosity. The soil skeleton can hence be modelled as an elastic fragile porous matrix, affected by the ordered collapse of its pores. Things are different in plastic soils, due to the significant reactivity of the montmorillonite minerals to changes in water content that results in significant changes of the initial porous matrix. The ordered adsorption of layers of water molecules in clay platelets with respect to the suction or stress applied, evidenced long time ago in Soil science through X-ray diffraction techniques, appear to be able to help better understanding various phenomena like the compression of plastic compressible soils and the hydration of compacted bentonites. Interestingly, it also applies to understand the effects of smectite minerals in the volume changes behaviour of the CallovoOxfordian claystone. These two mechanisms at nano and microscopic scales hence provide a better understanding of the macroscopic volume changes of a large variety of natural and compacted clayey soils and rocks.
\end{abstract}

Keywords: clayey soils and rocks; microstructure; montmorillonite; pore size distribution; nano scale; water adsorption. 
It is well admitted that microstructure effects have significant consequences on the macroscopic mechanical response of clayey soils and rocks. This was first observed when investigating the compression behaviour of sensitive clays of Eastern Canada, in which a sudden collapse is observed once overpassing the yield stress (e.g. Locat and Lefebvre 1985). This collapse was related to microstructure changes by Delage and Lefebvre (1984), who showed that sensitive Champlain clays are characterised by an aggregate microstructure, and that their compression is related to changes in pore size distribution. This concept, that will be detailed later in this paper, has been extended to unsaturated dry compacted soils, but could however not be extended to plastic soft compressible soils, because of the particular role played by the montmorillonite minerals (also called smectite) responsible of the high plasticity of these soils. In this case, pioneering data from X-ray diffraction techniques from Soil Scientists on the hydration of smectites evidenced some nano-scale mechanisms governing the clay-water interactions in hydrated smectites. These mechanisms also appeared to be valid to better understand the swelling behaviour of plastic soils, in particular in the case of compacted bentonite used as engineered barriers in radioactive waste disposal. More recently, it has been demonstrated that they also govern the swelling behaviour of claystone considered as possible host-rocks for radioactive waste disposal.

In this paper, the macroscopic hydro-mechanic volume changes of various clayey soils and rocks are interpreted with respect to these mechanisms occurring at the nano and microscales, for various saturated and unsaturated geomaterials of various plasticity indexes.

\section{Pore collapse compression mechanisms in low plastic clay soils and dry compacted soils}

The microstructure of sensitive clays was characterised by using a Jeol Cryoscan scanning electron microscope (SEM) that allowed to observe (Delage et al. 1982) the freeze fractured plane of a sensitive clay from Saint-Guillaume, a moderately plastic clay (low and moderate plastic soils are defined by $I_{p}<50$ according to Casagrande's classification) from the Champlain Sea, in the Province of Québec, with $80 \%<2 \mu \mathrm{m}, I_{\mathrm{p}}=22$, clay minerals mainly containing illite. The Cryoscan device allowed to minimise sample perturbations thanks to ultra-rapid freezing followed by freeze-fracturing. In such conditions, crypto-crystalline ice is formed, with no significant volume expansion (Gillott et al. 1973, Tovey and Wong 1973, Tessier and Berrier 1978, Delage and Pellerin 1984). Defining an observation plane by fracturing a frozen specimen also benefits from the fact that fracture is governed by the breakage of the ice, that acts as an impregnation resin keeping the microstructure intact during fracturing.

Observation of Figure 1 shows a typical aggregate microstructure, with inter-aggregates bridges made up of clay platelets and large inter-aggregates pores. This aggregate microstructure has also been observed in various other sensitive clays from the Champlain sea by Delage (2010), who investigated microstructure by the combined use of mercury intrusion porosimetry (MIP) and scanning electron microscopy. Figure 2 shows a SEM photo of SaintMarcel clay, and Figure 3 shows the pore size distribution (PSD) curves of intact, remoulded and dried freeze-dried specimens of Saint Marcel clay. The Figure shows a well sorted curve at intact state, with an average pore diameter of $0.18 \mu \mathrm{m}$ and $80 \%$ of the intruded pore 
volume in the range $0.1-0.3 \mu \mathrm{m}$. As shown in Delage (2010), this section of the PSD curve corresponds to the inter-aggregates porosity, whereas the smaller pores below $0.1 \mu \mathrm{m}$ corresponds to the intra-aggregate porosity. The average entrance diameter of $0.18 \mu \mathrm{m}$ is smaller than the average pore diameters of about $0.5-1 \mu \mathrm{m}$ observed in the photo of Figure 2 because of the constriction (or ink-bottle effect) resulting from the various clayey bridges crossing the inter-aggregate distance (see Figure 1 and 2). In other words, the average diameters detected by mercury during mercury intrusion in the inter-aggregates pores are smaller than the real pore diameters. This is also due to the tortuosity effects in the interaggregates pores.

Another important point observed on Eastern Canada sensitive clays is the conservation of aggregates after remoulding. This was directly observed in SEM photos in Delage \& Lefebvre (1984) on a specimen manually remoulded in the lab by using a spoon, and can also be seen on the PSD curve of a remoulded Saint-Marcel clay (Figure 3). The curve differs from that of the intact soil in the range of inter-aggregates porosity, and is superimposed in the intraaggregate porosity range, for pores with radius smaller than $0.8 \mu \mathrm{m}$. The weak points of the microstructure affected by remoulding are the clayey bridges joining the aggregates together, that are destroyed by remoulding. The order of magnitude of the inter-platelets bonds within the aggregates is obviously stronger, since they are not affected by remoulding, that keeps their intra-aggregates pores intact. This observation that the elementary microstructure unit involved (but not destroyed) by remoulding is the aggregate has also been made in Lapierre et al. (1990) who adopted the same methodology on another eastern Canada sensitive clay (Louiseville), and has recently been confirmed on a Swedish sensitive clay (Utby) by Birmpilis et al. (2019), based on an investigation conducted by using Small Angle X-ray Scattering (SAXS) and Digital Image correlation techniques (DIC).

Figure 3 also shows that the aggregates didn't resist to drying, that resulted in significant shrinkage, as shown by the much smaller intruded volume and average pore diameter. Only one well sorted pore population of very small radius $(38 \mathrm{~nm})$ is observed, showing that the inter-aggregate pores have been completely erased.

Unsurprisingly, the lower strength level at the inter aggregates level also governs the compression behaviour, as shown in Delage and Lefebvre (1984) on the Saint-Marcel Champlain clay. Indeed, the change in PSD curve of specimens of Saint Marcel clay submitted to various level of vertical stress in the oedometer (124, 421 and $1452 \mathrm{kPa}$, Figure 4) shows that compression progressively affects, in an ordered fashion, smaller and smaller interaggregates pores, starting from the largest ones (at around $1 \mu \mathrm{m}$ entrance radius) at yield stress $(54 \mathrm{kPa})$. As an example, the PSD curve at $124 \mathrm{kPa}$ clearly show that all pores with radius larger than $0.4 \mu \mathrm{m}$ have been collapsed, whereas those smaller than $0.3 \mu \mathrm{m}$ are still intact. Actually, the simultaneous presence of (larger) collapsed pores and (smaller) intact pores has been also observed in SEM, as described in Delage and Lefebvre (1984). Note also that in all cases, all PSD curves are similar in the intra-aggregate range, showing that the maximum vertical stress of $1452 \mathrm{kPa}$ is not high enough to compress the aggregates.

Indeed, this clear segregation in size of collapsed pores based on the vertical stress applied allowed to consider, in these sensitive clays, that the compression curve of intact samples could also be considered as a pore size distribution curve, as demonstrated by the good correspondence between the slope of the PSD curve $\left(C_{p}\right)$ and that of the compression curve 
(compression coefficient $C_{c}$ ) observed on 6 different Champlain clays by Delage \& Le Bihan (1986), Delage 2010 and 2014. In other words, the MIP investigation showed that a given compression stress increment will collapse a given population of pores defined by their size, starting from the larger ones (lower stress) and progressively collapsing smaller and smaller ones (at higher and higher stress). In each case, the decrease in volume provides the pore volume corresponding to the collapsed pores, that have their size related to the stress increment applied. The two parameters necessary to define a pore size distribution curve are hence met: the stress increment, related to the pore size, and the resulting decrease in volume, providing the corresponding porous volume (see Delage 2010 for more detail). As a consequence, Delage et al. $(2010,2014)$ observed that a more compressible soil (high $C c$ ) had a better sorted PSD (high $C p$ ).

135

136

137

138

139

140

141

142

143

144

145

146

147

148

149

150

151

152

153

154

155

156

157

158

159

160

161

162

163

164

165

166

167

Following the methodology of Delage and Lefebvre (1984) based on the combined use of SEM and MIP, similar observations have been made (Delage et al. 1996) on a low plasticity Jossigny silt compacted on the dry side $\left(w=14.9 \%, \rho_{\mathrm{d}}=1.63 \mathrm{Mg} / \mathrm{m}^{3}, S_{\mathrm{r}}=59 \%\right)$ of the Proctor optimum $\left(w_{\mathrm{Opt}}=18.3 \%, \rho_{\mathrm{d}-\mathrm{Opt}}=1.68 \mathrm{Mg} / \mathrm{m}^{3}, S_{\mathrm{r}-\mathrm{Opt}}=77 \%\right.$ ), observations that have been confirmed by others afterwards (e.g. Romero et al. 1999, Lloret et al. 2003). Figure 5a clearly shows that the microstructure on the dry side is also composed of aggregates, with a $110 \mu \mathrm{m}$ diameter aggregate composed of silt particles of $20-30 \mu \mathrm{m}$ average diameter. A $28 \mu \mathrm{m}$ inter-aggregate pores can also be observed below the aggregate, together with other ones surrounding the aggregate. Unsurprisingly, this work confirmed previous observations from Ahmed et al. (1974) about the bimodal nature of the PSD curve on the dry side of the Proctor optimum (Figure 6), that defines both the inter-aggregate porosity (average pore entrance radius 2.7 $\mu \mathrm{m}, 52 \%$ of the intruded porosity) and the intra-aggregate porosity (average pore entrance radius $0.28 \mu \mathrm{m}, 48 \%$ of the intruded porosity). Again, due to ink-bottle effects, the average entrance pore diameter of the inter-aggregate porosity detected by MIP is significantly smaller than the inter-aggregate pores observed in SEM.

The change in pore size porosity during compression has been derived (Delage and Graham 1995, Delage 2009) from earlier data of Sridharan et al. (1971) who run MIP tests in samples compacted at various densities at same water content of $21 \%$. The various PSD curves of Sridharan et al. (1971) are plotted together in Figure 7. Based on the hypothesis that, due to both capillarity and adsorption, water is contained in smaller pores, one can consider that the pores corresponding to intruded porosity below the $w=21 \%$ line (with entrance diameter smaller than $1 \mu \mathrm{m}$ ) are saturated. The changes in PSD curves with decreased porosity show that compression mainly concerns the larger inter-aggregate larger pores, located above the $21 \%$ line. Based on the zone in which PSD curves are superimposed, a limit value between the intra-aggregate porosity (the common section of the curves) and the inter-aggregate one (the section that changes with decrease in porosity), can be estimated at around $0.5 \mu \mathrm{m}$, which corresponds to a suction around $600 \mathrm{kPa}$ (using an air-solid interfacial tension value $\sigma_{\mathrm{s}}=72.75$ $\times 10^{-3} \mathrm{~N} / \mathrm{m}$ and, for the contact angle, $\cos \theta=1$ ). This would mean that, for suctions smaller than $600 \mathrm{kPa}$, some inter-aggregate menisci could exist, while having most of the interaggregate porosity filled by air. For suction larger than $600 \mathrm{kPa}$, menisci develop within the aggregate, and the inter-aggregate bonding results from adsorption effects through connecting contact governed by hydrated clay particles. The void ratio of 0.59 corresponds to a stage close to saturation, that is reached at $e=0.56$. 
A macroscopic consequence of this feature can be derived from monitoring the changes in suction at constant water content with density observed in various compacted soils, and reported in Figure 8 (Li et al. 1995, see also Gens et al. 1995) from data on a compacted loess $\left(I_{\mathrm{p}}=10\right)$. One can observe that constant suction extrapolated curves are close to vertical on the dry side, showing that compression at constant water content occurs at (almost) constant suction, with $s \approx 90 \mathrm{kPa}$ at $w=16.5 \%, s \approx 80 \mathrm{kPa}$ at $w=18 \%, s \approx 70 \mathrm{kPa}$ at $w=19 \%$. This trend changes when approaching to the Proctor optimum water content ( $w=20.5 \%$ ), where the constancy in suction only holds until dry a density value of $\gamma_{\mathrm{d}}=15.75 \mathrm{kN} / \mathrm{m}^{3}$. At larger dry densities, iso-suction curves become curved and progressively adopt, at largest values, inclinations close to that of the saturation curve. The constancy of suction at constant water content on the dry side is explained by the fact that, as observed in Figure 7, compression occurs by compression of the aggregate porosity full of air and mutual rearrangement of the aggregates. Suction, that is governed by capillary and physico-chemical clay water interaction within the aggregates, is not affected by compression, because the aggregates themselves are not compressed in the range of stress corresponding to this range of density and water content. The conservation of aggregates already observed in saturated sensitive clays is hence confirmed in unsaturated compacted soils, as also confirmed by others (e.g. Lloret et al. 2003).

The data of Figure 8 show that this is no longer valid on the wet side of the optimum (with $\left.w=21.5 \%>w_{\mathrm{Opt}}=18.3 \%, \rho_{\mathrm{d}}=1.63 \mathrm{Mg} / \mathrm{m}^{3}, S_{\mathrm{r}}=83.5 \%\right)$, an area where the aggregate structure is no longer observed. Indeed, as observed in Figure $5 \mathrm{~b}$, the microstructure is characterised by a clay matrix. In other words, the clay fraction of the Jossigny silt $(34 \%<2 \mu \mathrm{m})$ is fully hydrated, and the clay particles are no longer stuck along the faces of the silt grains as in the case of the dry compacted specimen. Once hydrated, their volume is much larger, and they are able to act as a clay matrix in which silt grains are embedded. As a consequence, as observed in Figure 6, the PSD curve is no longer bi-modal, as in the case of aggregate microstructures (see Delage et al. 1996 for more details). Although it is not clearly observable in the SEM photo, this area of high degree of saturation $\left(S_{r}>85 \%\right)$ should correspond to a zone with individual air bubbles not connected together. In this area, compression affects the clay matrix that governs the soil suction, which results in a decrease in suction with compression.

The general conclusion drawn from compression data in sensitive clays and dry compacted soils is that both soils are characterised by a rigid porous skeleton made up of aggregates bonded together with fragile bonds, and that compression occurs by the ordered and progressive collapse of inter-aggregate pores, with no effect on the intra-aggregate porosity. Of course, for natural saturated clays characterised by a rigid porous skeleton, this observation is only valid on intact specimens, given that the condition of rigid skeleton would not be valid for remoulded clays, due to the breakage of the rigid natural inter-aggregate bonds. The compression of an elastic fragile porous matrix containing pores of various diameters progressively collapsed according to their size has been modelled by means of the boundary elements method in Cerrolaza and Delage (1997), who observed a satisfactory shape of the compression curve. 
The previous mechanism can only work when the soil skeleton behaves as a rigid porous matrix, like in sensitive clays, that are known to have a Yield Stress Ratio (YSR) larger than 1 thanks to some bonding agents (Locat et al. 1984) that ensure their stability at intact state and are destroyed by remoulding. This is also true for dry compacted soils thanks to the interaggregate bonding at low water contents, that results from both capillary actions and physicochemical effects. This mechanism cannot however be extended to plastic compressible clays, as seen in Figure 9 that presents the PSD curves obtained at different levels of compression of a highly plastic clay $\left(w_{P}=52, w_{L}=139\right.$ and $\left.I_{p}=87\right)$ from the Gulf of Guinea (De Gennaro et al. 2005, Le 2008). The Figure does not present any superimposition of the PSD curves at various vertical loads, and one cannot conclude that the same ordered pore collapse mechanism occurs here as well. Note however that the SEM photo presented in Figure10 shows a microstructure not so different from that of the Saint-Guillaume clay (Figure 1). The Gulf of Guinea clay is characterised by large pores (diameter often larger than $1 \mu \mathrm{m}$ ) with clayey bridges linking together aggregated clay particles, with an overall microstructure somewhat similar to a honeycomb microstructure. The PSD curves present different shapes, with superimposition only observed on small pores (entrance pore radius smaller than $0.06 \mu \mathrm{m}$ ). Indeed, most of the pores are affected by loading under $50 \mathrm{kPa}$, showing that almost all microstructure levels are affected by compression. Note that some micro-organisms have been observed in this clay, as also done by Tanaka and Locat (1999) in some plastic Japanese marine clays. Tanaka and Locat however concluded that the effect of microorganisms was not significant at low stress, due to the mechanical resistance of the shells, compared to that of the surrounding assembly of clay particles. This is thought to be valid in our case, a least when applying the $50 \mathrm{kPa}$ load, during which a significant shift of the PSD curve was already observed. It is true that these effects would deserve a specific investigation at larger stress.

The main difference compared to Eastern Canada sensitive clays is that the clay fraction of the Guinea clay is characterised by a significant content of smectite (probably contained in illitesmectite species, common in clays of detritic origin occurring in complex natural media, Thomas et al. 2005), that explains the high plasticity of the clay. It is hence necessary to consider how smectite minerals behave under compression, based on literature data observed on montmorillonite suspensions. The area of the Gulf of Guinea is a place where the sedimentation of clay particles provided by the river Niger still occurs in a saline environment (around $35 \mathrm{~g} / \mathrm{l}$ of salt, mainly $\mathrm{NaCl}$ ), in quiet conditions, in such a way that the comparison with artificial clay suspensions is reasonable. Tessier et al. (1991) performed an investigation of the change in microstructure of saturated clay suspensions submitted to increased suction by means of the combined use of SEM, transmission electron microscopy (TEM) and Small Angle X-ray Scattering (SAXS). As observed by Marcial et al. (2002) on bentonite suspensions, the effect of increased suction in saturated conditions, in terms of global volumetric changes, is reasonably comparable to that of oedometer compression loading, showing that the contribution of the deviatoric part of the stress state in the oedometer has no significant effect in terms of global macroscopic volumetric response.

The SEM photo of a $\mathrm{Na}^{++}$smectite suspension submitted to increase suction $(3.2,100 \mathrm{kPa}$ and $1 \mathrm{MPa}$ ) presented in Figure 11 shows an initial honeycomb microstructure ( $w=369 \%$ under $3.2 \mathrm{kPa}$ ) characterised by large pores (up to $2 \mu \mathrm{m}$ ) separated by walls made up of the stacking of montmorillonite layers. The TEM photo of Figure 12 shows in more details the structure of 
the wall, made up here of $30-50$ elementary layers in face to face arrangements. The SEM photos clearly show how the pores are compressed when increasing suction (the changes in height of the photos corresponds to the change in height due to compression), with elongated pore shapes observed under $100 \mathrm{kPa}$. Better understanding of the change in microstructure are provided by SAXS measurements, who are able to give the changes in thickness of the walls as well as the inter-layer distances. Actually, it is known for long time (e.g. Mooney et al. 1952, Norris 1954, Méring \& Glaeser 1954 and, more recently Berend et al. 1995 and Ferrage et al. 2005) that the inter-layer distance between montmorillonite layers within stacks depends on the number of layers of water molecules adsorbed along the montmorillonite minerals, which in turn depends of the suction applied. Typically, to give orders of magnitudes, various hundreds of MPa correspond to one adsorbed layer (1W hydration) with an inter-basal spacing of $12.6 \AA$, various tens of MPa correspond to two layers ( 2 W hydration) with an interbasal spacing of $15.6 \AA$ whereas three layers (3W hydration) with an inter-basal spacing of 18.6 ̊ appear for suctions smaller than 7-9 MPa. Tessier (1991) investigated in more details the change in the wall configuration of $\mathrm{a} \mathrm{Ca}^{++}$montmorillonite and provided the changes in wall thickness and number of layers of the wall with respect to suction. He showed that, at lower suctions ( 3.3 and $100 \mathrm{kPa}$ ), the walls were made up of 55 layers with an inter-basal spacing of $18.6 \AA$ ( $3 W$ hydration), whereas this number increased up to 225 with the same $3 W$ hydration under $1000 \mathrm{kPa}$. At higher suction, the inter-basal spacing reduced to $15.6 \AA$ ( $2 \mathrm{~W}$ hydration) whereas the number of layers of the walls increased to 400 . There is unfortunately no such data for $\mathrm{Na}^{++}$montmorillonite, but SAXS data indicate that the compression mechanisms simultaneously involve the decrease in the size of pores, as observed in SEM, and a change in the configuration of the wall, with a significant enlargement of the number of layers with stress. Although the link with the changes in PSD curves is not obvious, one can suspect that the changes in microstructure that govern the shape of the various PSD curves observed in Figure 9 are affected by this kind of phenomenon with a thickening of the walls of the honeycomb microstructure and, in the range of stress considered (up to $1 \mathrm{MPa}$ ), a $3 \mathrm{~W}$ hydration with three layers of water adsorbed along the montmorillonite layers within the walls. Note also that the water molecules located in the large pores close to the surface of the walls may also be affected by Diffuse Double Layer effects resulting from the electrical deficit of the montmorillonite layer along the wall. The main difference of this compression mechanism involving smectite minerals, compared to the previous case corresponding to a porous fragile matrix typical of low plastic soils, is linked to the reactivity of smectite minerals with water, that changes the nature of the clay matrix under compression, with the combined effect of decrease in pore size and modifications in the wall structure due to both change in the $\mathrm{nW}$ hydration within the wall, and in number of layer that constitute the walls.

The swelling of heavily compacted bentonites

Various Engineered Barriers Systems (EBS) are foreseen as barrier and plug for galleries in geological radioactive waste disposal. EBS can be used as compacted bricks, pellets or granular bentonite and placed around the waste canisters to provide a supplementary isolation layer with respect to that provided by the host rock. EBS are made up of relatively pure montmorillonites, like those described in Table 1 (FoCa7 from France, Kunigel from Japan, MX80 from Wyoming, USA and GMZ from China), considered as possible components of EBS in various countries. As seen in the Table, bentonites are characterised by significantly high liquid limit (up to 520 for MX80), specific surface (up to $700 \mathrm{~m}^{2} / \mathrm{g}$ for MX80) and cation 
exchange capacity (up to $73.2 \mathrm{mEq} / 100 \mathrm{~g}$ for Kunigel). The old findings on bentonite hydration mentioned above appeared also valid for compacted bentonites, as shown in Figure 13, from a SAXS investigation of hydration conducted by Saiyouri et al. (2004). The suction limits corresponding to changes in $\mathrm{nW}$ hydration are clearly defined with the transition $1 \mathrm{~W}-2 \mathrm{~W}$ occurring at $50 \mathrm{MPa}$ and that between $2 \mathrm{~W}$ and $3 \mathrm{~W}$ at $7 \mathrm{MPa}$. It is important to also note the decrease in number of layers per platelet that starts at 350 above $50 \mathrm{MPa}$, decreases to 150 at the $2 \mathrm{~W}-3 \mathrm{~W}$ transition at $7 \mathrm{MPa}$ prior to reduce at 10 layers below $3 \mathrm{MPa}$. Note also that the constitution of a $4^{\text {th }}$ layer occurs at low suction below $100 \mathrm{kPa}$. Interestingly, these hydration data follow the same trend as what was observed by Tessier (1991) on montmorillonite suspensions along a drying path, with $3 \mathrm{~W}$ hydration under $1 \mathrm{MPa}$ and $2 \mathrm{~W}$ hydration under $10 \mathrm{MPa}$, coupled by an enlargement in thickness of the wall from 55 layers at $100 \mathrm{kPa}$ to 225 at $1 \mathrm{MPa}$ and 400 layers at $10 \mathrm{MPa}$. Saiyouri et al. (2004) observed similar trends on other compacted bentonites than MX80. Based on this, one can then consider that the microstructure of the compacted Kunigel bentonite hydrated a low suction with free swelling, as observed in Figure 14 (Cui et al. 2002), has walls made up of around 10 layers with $4 \mathrm{~W}$ hydration and an inter-basal thickness of $21.6 \AA$, resulting in an estimated thickness of around $21 \mathrm{~nm}$. These walls delimit pores of various micrometres diameters, comparable with those observed in the montmorillonite suspension of Figure 11.

The $\mathrm{nW}$ hydration mechanism also helps better understanding the changes in PSD curve of MX80 compacted samples at same density but different water content, presented in Figure 15. Both samples have a void ratio $e$ close to 1 , but the wetter sample at a water content $w=$ $28.5 \%$ has a suction of $2 \mathrm{MPa}$, whereas that at $w=12.5 \%$ has a larger suction of $30 \mathrm{MPa}$. Both curves exhibit a bi-modal PSD allowing to distinguish the (comparable) inter-aggregate porosity, with entrance pore radius close to $2 \mu \mathrm{m}$, from the intra-aggregate porosity where more difference is observed, with an entrance radius of $19 \mathrm{~nm}$ for the drier sample at $s=30$ $\mathrm{MPa}$, compared to $10 \mathrm{~nm}$ for the wetter sample at $\mathrm{s}=2 \mathrm{MPa}$. Another significance difference is observed in the infra-porosity, defined in Delage et al. (2006) as corresponding to the pores with entrance radius smaller than $3.5 \mathrm{~nm}$, too small to be intruded by mercury in MIP. The infra-porosity of the wetter sample (with $e_{\text {infra }}=0.156$ ) is smaller than that of the drier sample $\left(e_{\text {infra }}=0.363\right)$.

The hydration mechanisms described in Figure 13 indicates that, under $2 \mathrm{MPa}$, the wetter sample is in a $3 \mathrm{~W}$ hydration state with inter-basal spacing of $18.3 \AA$ and thin platelets made up of around 10 layers, resulting in an estimated thickness of $18 \mathrm{~nm}$. Based on the brick model, in which clay platelets within the aggregate are compared to a brick assembly, the brick thickness can be estimated as the average entrance diameter detected in MIP (see Yven et al. 2007 and Menaceur et al. 2016). This provides an estimated thickness of $20 \mathrm{~nm}$ (for an entrance radius of $10 \mathrm{~nm}$, see Figure 15), in good agreement with the $18 \mathrm{~nm}$ estimation derived from the hydration mechanism. At $30 \mathrm{MPa}$, the drier sample is in a $2 \mathrm{~W}$ hydration state with $15.3 \AA$ inter-basal spacing, and much thicker particles of around 250 layers, resulting in an average thickness of $38 \mathrm{~nm}$. With an entrance pore radius of $19 \mathrm{~nm}$ (Figure 15), the thickness estimated from the brick model and MIP is $38 \mathrm{~nm}$, quite in good agreement with the estimation from the hydration mechanism.

The difference in infra-porosity can also be commented. The amount of inter-layer water molecules adsorbed along the montmorillonite layers is higher in the wetter sample, with $4 \mathrm{~W}$ hydration, compared to that in the drier sample at $2 \mathrm{~W}$ hydration. Assuming that the 
montmorillonite surface along which water molecules are adsorbed in both cases is the same because they have the same density, one can conclude that there are twice more water molecules adsorbed in the wetter case, a proportion which corresponds well with the ratio of infra-porosity ( 0.156 in the drier case and 0.363 in the wetter case). All these observations show the validity of the conclusions drawn from SAXS investigations on the hydration mechanisms in compacted bentonite, and how MIP data can be further interpreted to get a more complete understanding of the effects of changes in water content on the microstructure of compacted bentonites.

\section{Volume changes in swelling claystones}

Particular attention has been paid in the last decades on the hydro-mechanical behaviour of claystones considered as possible host-rocks for deep geological waste disposal in Europe, i.e. the Callovo-Oxfordian claystone in France and the Opalinus Clay in Switzerland. A detailed investigation on the volume changes in free conditions of the Callovo-Oxfordian (COx) claystone under controlled suction changes (Menaceur et al. 2016) demonstrated that the hydration mechanisms commented above also play a role within the montmorillonite minerals present in illite-smectite mixed layer clay minerals of the COx clay matrix (see also Delage et al. 2014). This matrix (with more than $45 \%<2 \mu \mathrm{m}$ ) can be observed in the SEM photo of a freeze-fractured plane of a COx sample hydrated at zero suction, presented in

Figure 16 (Menaceur 2014). The clay matrix is clearly apparent with a well-marked bedding plane close to horizontal, and some footprints of detritic minerals ( $25 \%$ calcite grains, $20 \%$ quartz grains, see Gaucher et al 2004) that have been extracted from the fracture plan during freeze-fracturing (after ultra-quick freezing of small sticks of claystone in slush nitrogen at $210^{\circ} \mathrm{C}$, see Delage et al. 2006). Pyrite crystals are also observed. The photo also clearly shows that (free) swelling under zero suction (around 6\%) resulted in the development of large subhorizontal cracks following the bedding plane, with $4 \mu \mathrm{m}$ width and more than $10 \mu \mathrm{m}$ length. Note that those cracks, also detectable by MIP, are typical of fully hydrated specimens and have not been detected in specimens extracted and kept at initial water content (Menaceur et al. 2016), showing that they are not due to stress release. Actually, as shown by Bornert et al. (2010) based on Digital Image Correlation on Environmental SEM images, swelling is also related, besides those mesoscopic cracks, to the development of smaller cracks and to some bulk deformation within the clay matrix.

The PSD curves of three freeze-dried COx specimens at suctions of $34 \mathrm{MPa}$ (initial state, as received in the lab), $150 \mathrm{MPa}, 331 \mathrm{MPa}$ together with that of a dry specimen (48h in an oven at $105^{\circ} \mathrm{C}$ ) are presented in Figure 17, together with the corresponding water retention curve, represented in terms of volume changes (measured by hydraulic weighing on waxed specimens) with respect to suction changes (Wan et al. 2013, Menaceur et al. 2016). One observes that there is a decrease in the average entrance pore diameter from $32 \mathrm{~nm}$ at 34 MPa suction down to $28 \mathrm{~nm}$ for both specimens under 150 and $331 \mathrm{MPa}$ suctions. The diameter then decreases to $21 \mathrm{~nm}$ in the dry state, in accordance with the data of Boulin et al. (2008). Considering that, based on the brick model and a simplified model of the microstructure of the COx claystone (see Yven et al. 2007 and Menaceur et al. 2016), the average entrance pore diameter provides a reasonable order of magnitude of the average platelet thickness, one can deduct from the dry state (with $0.96 \AA$ inter-basal spacing) that the 
average number of layers per platelet is equal to $21 / 0.96=22$. By considering a smectite proportion of $50-70 \%$ (Yven et al. 2007) in the mixed-layered illite-smectite platelets and considering $1 \mathrm{~W}$ hydration (12.6 ̊ inter-basal spacing) at 150 and $330 \mathrm{MPa}$, one estimate an average platelet thickness of $24.3-25.6 \mathrm{~nm}$, in reasonable agreement with the average entrance pore radius of $28 \mathrm{~nm}$ detected in MIP. Similarly, $2 \mathrm{~W}$ hydration (15.6 ̊ inter-basal spacing) for specimens at 34 and $9 \mathrm{MPa}$ provides an average thickness of $27.6-30.2 \mathrm{~nm}$, comparable to the $32 \mathrm{~nm}$ average entrance diameter detected by MIP. This good correspondence is illustrated in Figure 18, that shows the measured and estimated platelet thicknesses along the drying path. An interesting similarity is observed with the data presented in Figure 13, showing that the same hydration mechanisms occurs along the faces of the smectite layers contained in the COx clay matrix. This feature is further confirmed by considering the wetting path between 34 and $9 \mathrm{MPa}$, along which no significant volume change is observed in the water retention curve, in spite of a significant decrease of $25 \mathrm{MPa}$ in suction. It is shown in Menaceur et al. (2016) that both PSD curves at 34 and 9 MPa are similar, with comparable entrance pore diameter (as also observed in Figue 18), indicating that the COx claystone is probably in a $2 \mathrm{~W}$ hydration state at natural state.

MIP investigation also provided better understanding of the significant swelling (around 6\%) occurring below $9 \mathrm{MPa}$ (up to full saturation), a suction value below with $3 \mathrm{~W}$ hydration starts, followed by $4 \mathrm{~W}$ hydration at zero suction. The micro-cracks observed in Figure 16 at full saturation have also been detected by MIP by Menaceur et al. (2016), with some detected pores at 12 and around $0.1 \mu \mathrm{m}$.

Although they are quite different in nature, the same mechanisms govern the hydration of smectite suspensions, compacted bentonite and a swelling claystone like the COx claystone. In the latter case, this shows that the level of energy governing crystalline swelling in claystones is strong enough to break the long term diagenetic bonds that have developed during the long geological history of this claystone (158 millions years old). Swelling occurs both at the crystalline nanoscale level, with the ordered adsorption of layers of water molecules along the smectites layers within the platelets, and larger micrometre scale, by the development of micro-cracks that are responsible of most of the swelling at low suction (see Wan et al. 2013 and Menaceur et al. 2016). Note also that this significant reactivity of the smectite phase in swelling claystone is responsible of the remarkable self-sealing properties observed in both the Callovo-Oxfordian claystone and the Opalinus clay, in which open cracks are progressively filled by hydrated smectites that finally bring back the permeability of the cracked claystone to that of the intact rock (e.g. Davy et al. 2007, Menaceur et al. 2015).

\section{Concluding remarks}

The nano and micro-scale mechanisms described in this work to interpret the macroscopic volume changes of various geomaterials result from long-term investigations carried out on various clayey soils and rocks specimens as different as low and high plasticity compressible soils, smectite suspensions, compacted bentonites and swelling claystones. Two main mechanisms have been identified. In low plastic saturated and unsaturated materials, like sensitive clays or dry compacted silts, an aggregate microstructure was evidenced, and it was shown that compression is due to the progressive and ordered collapse of the inter aggregates pores, from the larger to the smaller. The soil skeleton hence reacts as an elastic fragile porous 
matrix, in which a given level of stress collapses a pore population whose diameter can be related to the stress applied. Also, it was shown that aggregates are able to resist to the action of stress currently applied in common geotechnical practice, and up to $1.5 \mathrm{MPa}$ in the case of sensitive clays from Eastern Canada. Another consequence of the aggregate stability in dry compacted soils is that compression at constant water content does not result in any change in suction.

The mechanisms of smectite hydration and compression that have been evidenced by Soil scientists in smectite suspensions based on X-ray diffraction techniques appeared to be relevant to better understand the compression of a highly plastic clay from the Gulf of Guinea, that is governed by quite different mechanisms that the above-mentioned ones. Indeed, the high reactivity of smectite minerals result in more complex mechanisms upon compression, with no clear collapse of any pore population, but a decrease in size of the pores coupled to both a reorganization affecting the thickness of the walls and the $n W$ hydration of the platelets they are made of. Interestingly, nW hydration steps also govern the hydration of compacted bentonite, and help better understanding the effects of changes in water content on their microstructure. They are also valid when describing the volume changes of swelling claystones due to crystalline swelling, and their high-energy level appears able to break, upon hydration, the diagenetic long term bonds that are at the origin of the high cohesion that they have gained and that progressively transformed the clay sediment in a clay rock.

Among other things, the investigations described in this paper didn't address the effects of pore water salinity on the macroscopic behaviour of intact clayey soils and rocks. Such effects, particularly significant in the smectite fraction of plastic clayey materials, can be described by using the Diffuse Double Layer theory, that provides some modelling of the effects of both the valence and the concentration of dissolved ions. This is however mainly valid in clay suspensions, and it seems that accounting for such effects in structured clays is still a pending problem, that obviously needs further investigation.

\section{References}

1. Ahmed S., Lovell C.W., Diamond S. (1974) Pore sizes and strength of compacted clay. ASCE Journal of Geotechnical Engineering 100(4): 407-425.

2. Bérend I., Cases J.M., François M., Uriot J.P., Michot L.J., Masion A., Thomas F. 1995. Mechanism of adsorption and desorption of water vapour by homoionic montmorillonites: 2 .

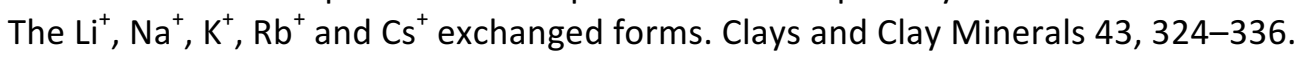

3. Birmpilis G., Hall S. A., Lages S. \& Dijkstra J. 2019. Monitoring of the nano-structure response of natural clay under mechanical perturbation using small angle $\mathrm{X}$-ray scattering and digital image correlation. Acta Geotecnica, doi.org/10.1007/s11440-019-00832-8.

4. Bornert M., Valès F., Gharbi H. and Nguyen Minh D. 2010. Multiscale Full-Field Strain Measurements for Micromechanical Investigations of the Hydromechanical Behaviour of Clayey Rocks. Strain 46, 33-46.

5. Boulin P.F., Angulo-Jaramillo R., Daian J.F., Talandier J., Berne P. 2008. Pore gas connectivity analysis in Callovo-Oxfordian argillite. Applied Clay Science 42(1-2):276-283.

6. Cerrolaza M. \& Delage P. 1997. Microstructure and volume change behaviour of soft clays: a boundary elements simulation. International Journal for Analytical and Numerical Methods in Geomechanics, 21, 665-686. 
7. Cui Y.J, Loiseau C. \& Delage P. 2002. Microstructure changes of a confined swelling soil due to suction controlled hydration. Proceedings of the 3nd International Conference on Unsaturated Soils, UNSAT'2002 (2), 593-598, Recife, Brazil, Balkema.

8. Davy C.A., Skoczylas F., Barnichon J.D., Lebon P. 2007. Permeability of macro-cracked argillite under confinement: gas and water testing. Physics and Chemistry of the Earth 32(8-14), 667680.

9. De Gennaro V., Delage P. \& Puech A. 2005. On the compressibility of deepwater sediments of the Gulf of Guinea. Proc. Int. Symp. Frontiers in Offshore Geotechnics (ISFOG 2005), 1063-1069, Perth (Australia).

10. Delage P., Tessier D. \& Marcel-Audiguier M. 1982. Use of the Cryoscan apparatus for observation of freeze-fractured planes of a sensitive Quebec clay in scanning electron microscopy. Canadian Geotechnical Journal 19 (1), 111-114.

11. Delage P. \& Lefebvre G. 1984. Study of the structure of a sensitive Champlain clay and its evolution during consolidation. Canadian Geotechnical Journal 21 (1), 21-35.

12. Delage P. \& Pellerin F.M. 1984. Influence de la lyophilisation sur la structure d'une argile sensible du Québec. Clay Minerals 19, 151-160.

13. Delage P. \& Graham J. 1995. The mechanical behaviour of unsaturated soils. Proceedings of the 1st International Conference on Unsaturated soils, Vol. 3, 1223-1256, Paris, Balkema.

14. Delage P., Audiguier M., Cui Y.J. \& Howat M.D. 1996. Microstructure of a compacted silt. Canadian Geotechnical Journal, 33 (1), 150-158.

15. Delage P. 2010. A microstructure approach of the sensitivity and compressibility of some Eastern Canada sensitive clays. Géotechnique 60 (5), 353-368.

16. Delage P., Marcial D, Cui Y J and Ruiz X. 2006. Ageing effects in a compacted bentonite: a microstructure approach. Géotechnique 56 (5), 291-304.

17. Delage P. 2009. Compaction behaviour of clay: discussion. Géotechnique 59 (1), 75-76.

18. Delage P. 2014. The oedometer compression curve is a pore size distribution curve in loose structured clays. Proc. TC105 International Symposium on Geomechanics from micro to macro (2), $1251-1254$, K. Soga et al. eds, CRC Press. Cambridge, UK.

19. Delage P. et Le Bihan J.P. 1986. Microstructure \& compressibilité d'argiles molles sensibles de I'Est canadien. Comptes-Rendus de l'Académie des Sciences 303, série II, n 19, 1697-1702, Paris.

20. Delage P., Menaceur H., Tang A.M. and Talandier J. 2014. Suction effects in deep CallovoOxfordian claystone. Géotechnique Letters 4, 267-271.

21. Ferrage E., Lanson B., Sakharov B.A., Drits V.A. 2005. Investigation of smectite hydration properties by modeling experimental X-ray diffraction patterns: part I. Montmorillonite hydration properties. American Mineralogist 90, 1358-1374.

22. Gaucher G., Robelin C., Matray J.M., Négrel G., Gros Y., Heitz J.F., Vinsot A., Rebours H., Cassagnabère M., Bouchet A. 2004. ANDRA underground research laboratory: interpretation of the miner- alogical and geochemical data acquired in the Callovian- Oxfordian formation by investigative drilling. Phys Chem Earth 29: 55-77.

23. Gens A. Alonso E.E. Suriol J. \& Lloret A. 1995. Effect of structure on the volumetric behaviour of a compacted soil. Proceedings of the $1^{\text {st }}$ International Conference on Unsaturated Soils UNSAT' 95, 1, 83-88.

24. Gillott J.E. 1973. Methods of sample preparation for microstructural analysis of soil. In: Rutherford GK (ed.), Proceedings of 4th international working meeting on soil micromorphology, Kingston, pp 143-164.

25. Lloret, A., Villar, M., Sanchez, M., Gens, A., Pintado, X. \& Alonso, E. E. (2003). Mechanical behaviour of compacted bentonite under high suction changes. Géotechnique 53 (1), 27-40.

26. Locat J. \& Lefebvre G. (1985). The compressibility and sensitivity of an artificially sedimented clay soil: the Grande Baleine marine clay. Marine Georessources and Geotechnology 6 (1), 127. 
27. Romero, E., Gens, A. \& Lloret, A. 1999. Water permeability, water retention and microstructure of unsaturated compacted Boom clay. Engineering Geology 54 (1-2), 117-127.

28. Tessier D. \& Berrier J. 1978. Observations d'argiles hydratées en microscopie électronique à balayage. Importance et choix de la technique de préparation. Proceedings of the 5th Intrnational Working-Meeting on Soil Micromorphology, Granada, 117- 135.

29. Tessier D. 1991. Behaviour and microstructure of clayey minerals. In Soils colloids and their association in aggregates, de Boodt M., Hayes M. and Herbillon A. eds, Plenum publishing Corporation.

30. Tovey N.K., Wong K.Y. 1973. The preparation of soils and other geological materials for the scanning electron microscope. Proceedings of the international symposium on soil structure, Gothenburg, Sweden, pp 176-183.

31. Lapierre, C., Leroueil, S. \& Locat, J. 1990. Mercury intrusion and permeability of Louiseville clay. Canadian Geotechnical Journal 27 (6), 761, 773.

32. Le M.H. 2008. Etude du comportement de sédiments marins profonds. PhD thesis, Ecole des Ponts ParisTech (in French).

33. Li Z.M. 1995. Compressibility and collapsibility of compacted unsaturated loessial soils. Proceedings of the $1^{\text {st }}$ International Conference on Unsaturated Soils UNSAT' 95 1, 139-144, Paris, Balkema, Rotterdam.

34. Lloret, A., Villar, M. V., Sanchez, M., Gens, A., Pintado, X. \& Alonso, E. E.: Mechanical behaviour of heavily compacted bentonite under high suction changes. Géotechnique 53, No. 1, 27-40 (2003).

35. Locat, J., Lefebvre, G. \& Ballivy, G. (1984). Mineralogy, chemistry and physical properties interrelationships of some sensitive clays of Eastern Canada. Canadian Geotechnical Journal 21 (3), $530-540$.

36. Marcial D., Delage P. \& Cui Y.J. 2002. On the high stress compression of bentonites. Canadian Geotechnical Journal 39 (4), 812-820.

37. Menaceur H. 2014. Comportement thermo-hydro-mécanique et microstructure de l'argilite du Callovo-Oxfordien. Thèse Ecole des Ponts ParisTech - Université Paris Est.

38. Menaceur H., Delage P., Tang A.M. and Conil N. 2015. On the Thermo-Hydro-Mechanical behaviour of a sheared Callovo-Oxfordian claystone sample with respect to the EDZ behaviour. Rock Mechanics and Rock Engineering, 49(5), 1875-1888.

39. Menaceur H., Delage P., Tang A.M. and Talandier J. 2016. The status of water in swelling shales: an insight from the water retention properties of the Callovo-Oxfordian claystone. Rock Mechanics and Rock Engineering 49 (12), 4571- 4586.

40. Méring J. \& Glaeser R. 1954. Sur le rôle de la valence des cations échangeables dans la montmorillonite. Bulletin de la Société Francaise de Minéralogie et Cristallographie 77: 519530.

41. Mooney R.W., Keenan A.C., Wood L.A. 1952. Adsorption of water vapor by montmorillonite. II. Effect of exchangeable ions and lattice swelling as measured from X-ray diffraction. Journal of the American Chemical Society 74:1371-1374.

42. Norrish K. 1954. The swelling of montmorillonite. Discussion Faraday Society 18:120-133.

43. Saiyouri, N., Tessier, D. \& Hicher, P.Y. 2004. Experimental study of swelling in unsaturated compacted clays. Clay Minerals 39, $469-479$.

44. Sridharan A., Altschaeffl A.G., Diamond S. 1971. Pore size distribution studies. ASCE Journal of the Soil Mechanics and Foundations Division 97(5): 771-787.

45. Tanaka H. and Locat J. 1999. A microstructural investigation of Osaka Bay clay: the impact of microfossils on its mechanical behaviour. Canadian Geotechnical Journal $36: 493-508$.

46. Thomas, F., Rebours, B., Nauroy, J.-F. \& Meunier, J. 2005. Minerological characteristics of Gulf of Guinea deepwater sediments. In Frontiers in Offshore Geotechnics ISFOG 2005, Proc. Int. Symp., Perth, 19-21 September 2005. Rotterdam, Balkema. 
47. Tovey N.K. \& Wong K.Y. 1973. The preparation of soils and other geological materials for the scanning electron microscope. In: Proceedings of the international symposium on soil structure, Gothenburg, Sweden, pp 176-183.

48. Wan M., Delage P., Tang A.M., Talandier J. 2013. The water retention properties of the Callovo-Oxfordian Claystone. International Journal of Rock Mechanics and Mining Sciences 64, 96-104.

581

582

583

584

49. Yven B., Sammartino S., Geroud Y., Homand F., Villieras F. 2007. Mineralogy, texture and porosity of Callovo-Oxfordian claystones of the Meuse/Haute-Marne region (Eastern Paris Basin). Mémoires de la Société Géologique de France 178: 73-90.

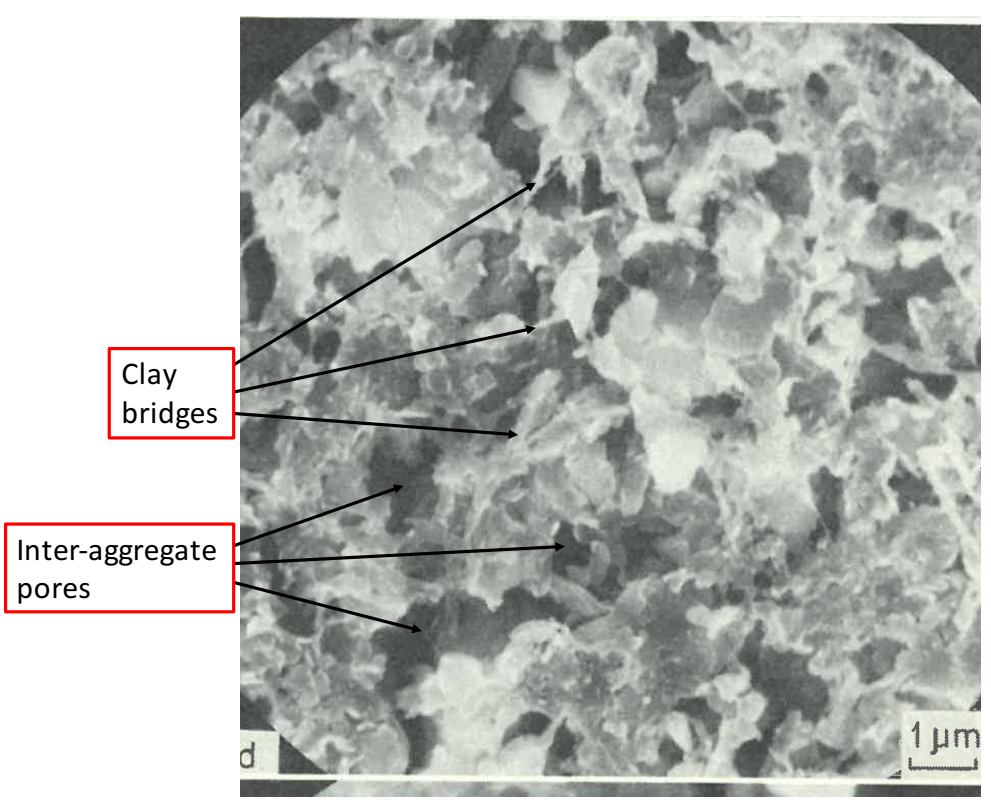

Figure 1. Scanning electron microscope photo of the Saint-Guillaume Eastern Canada sensitive clay.

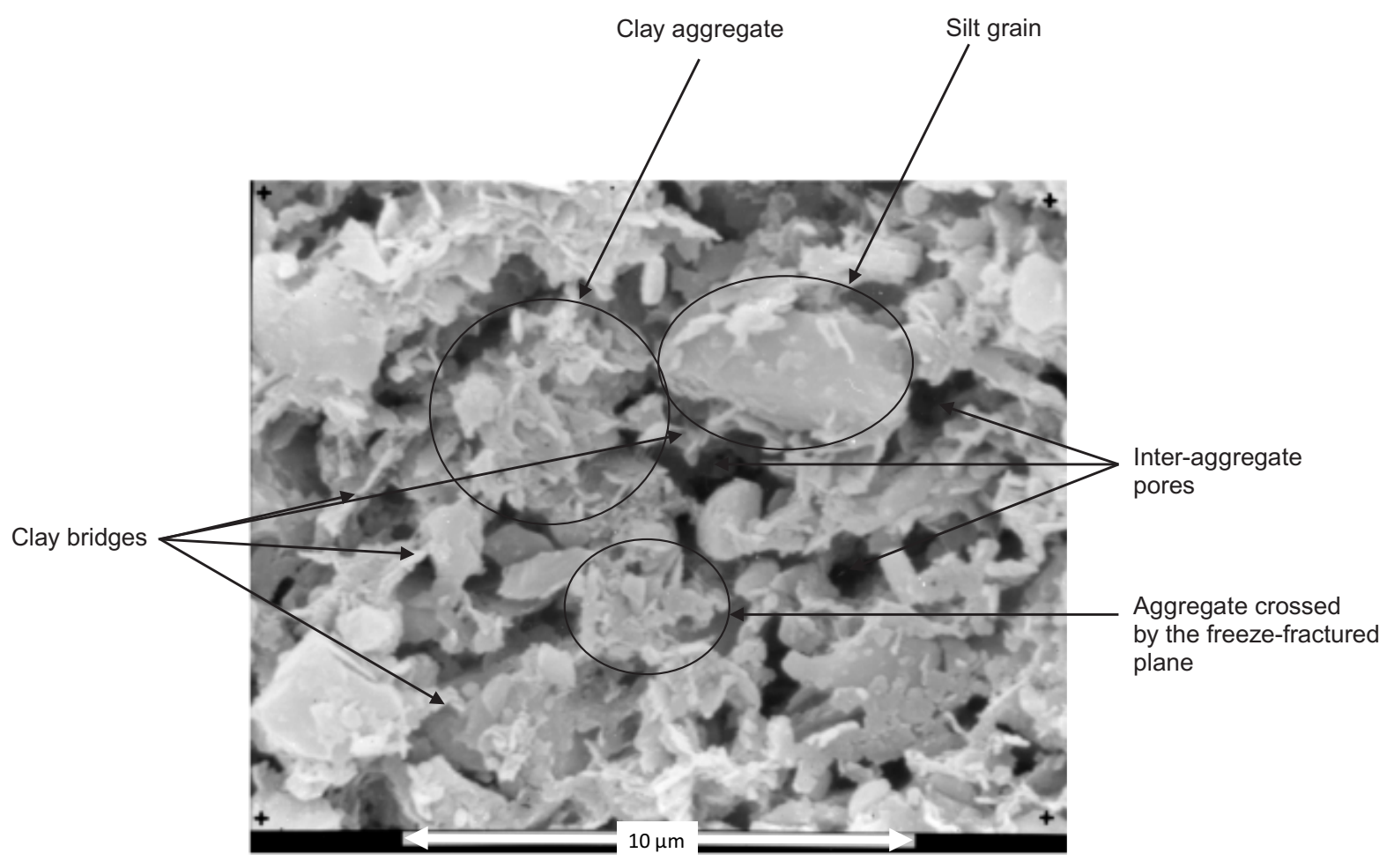




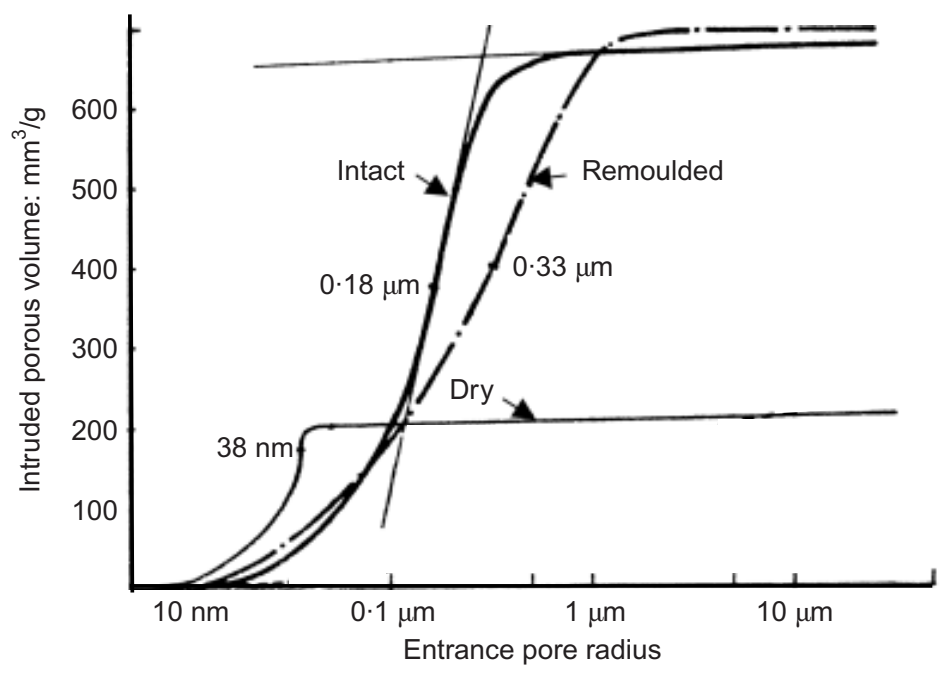

592

Figure 3. Pore size distribution curves of the Saint Marcel clay, intact, remoulded and dry states (Delage 2010).

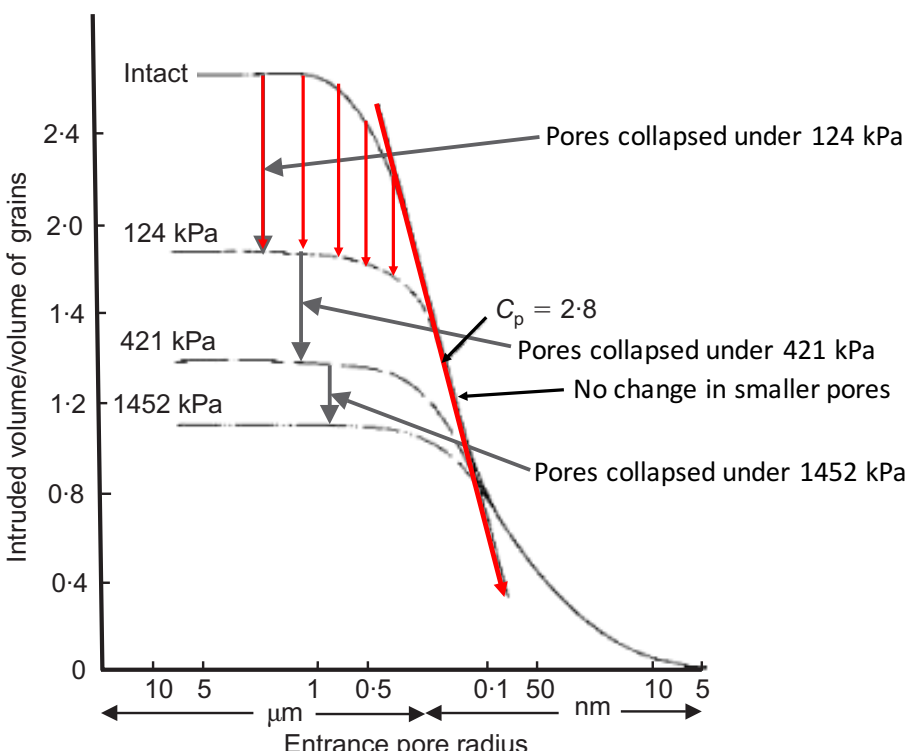

595 Figure 4. Pore size distribution of the Saint Marcel clay, intact and submitted to oedometer compression under 596124,421 and $1452 \mathrm{kPa}$ (Delage and Lefebvre 1984) 


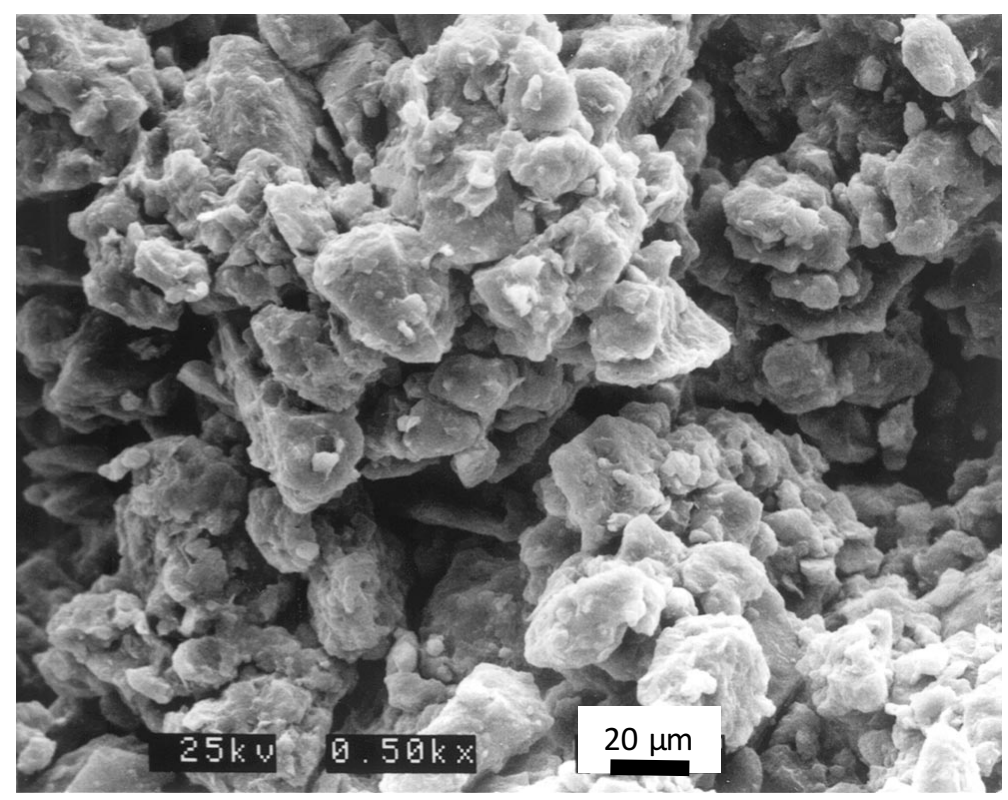

598

a)

599

600

601

602 603

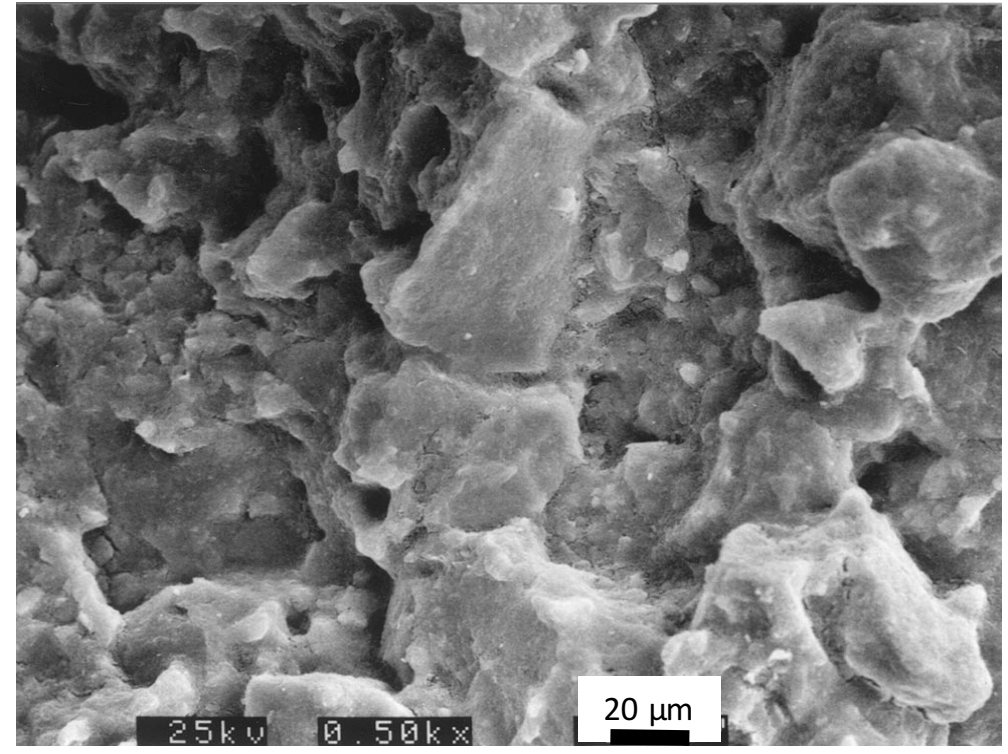

b)

Figure 5. SEM observation of compacted Jossigny silt: a) dry side of optimum; b) wet side of optimum. 
604
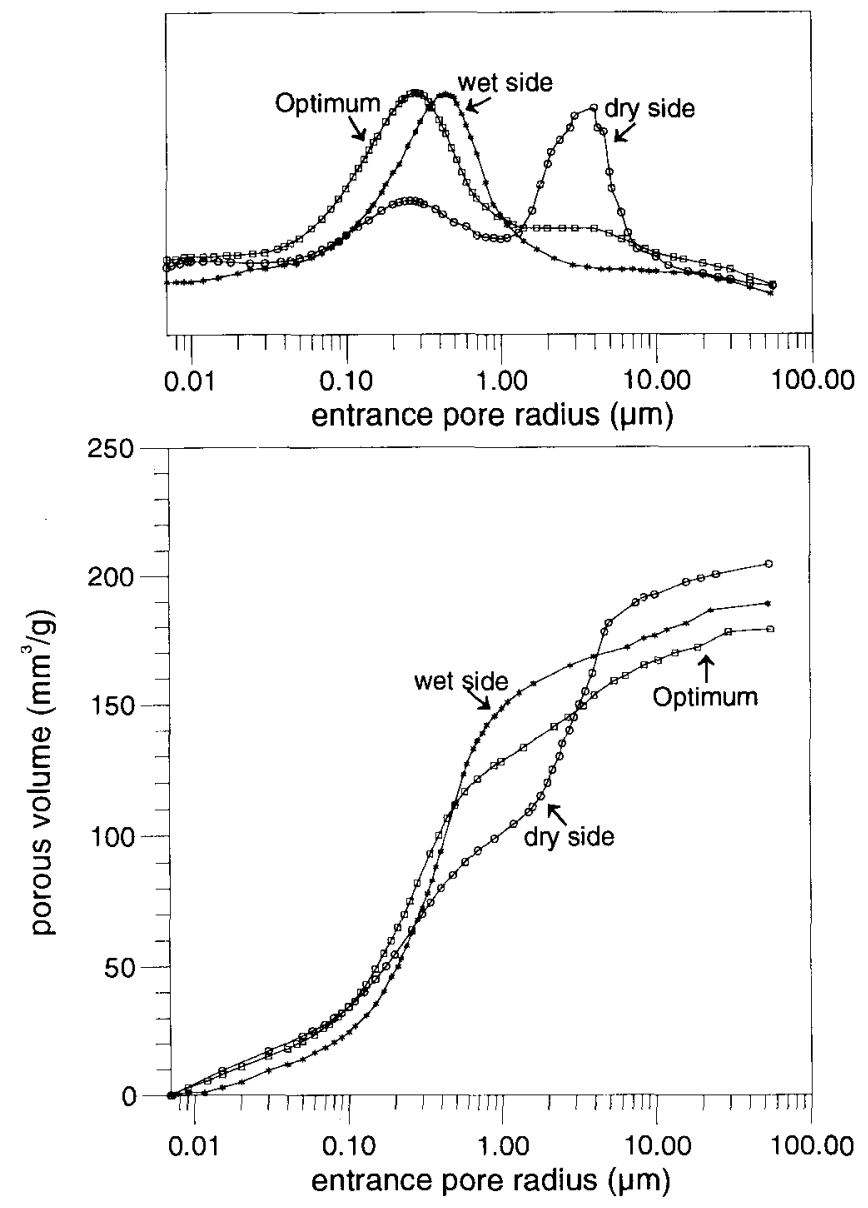

605 Figure 6. PSD curves of compacted Jossigny silt (Delage et al.1996).

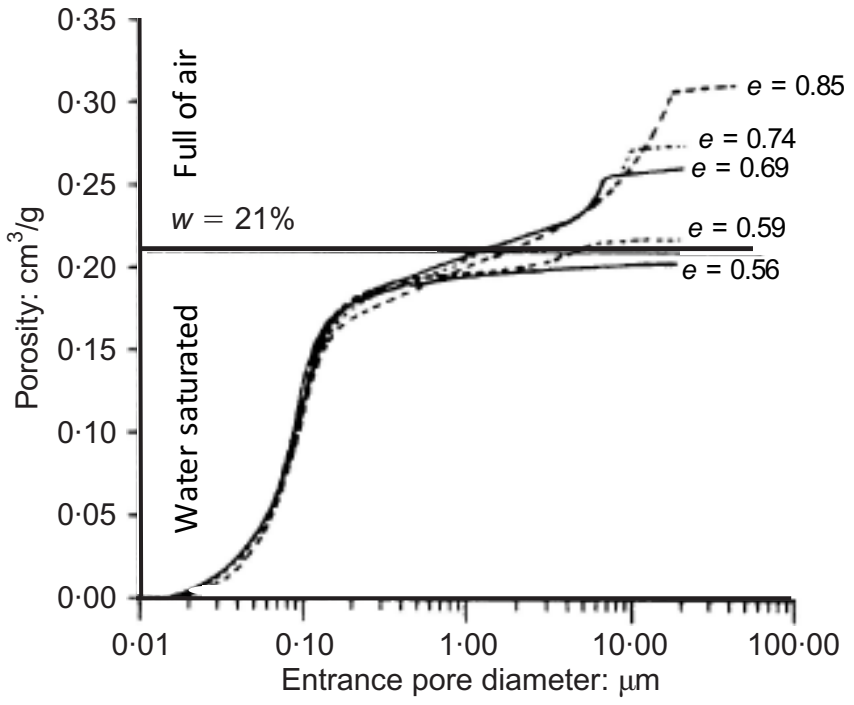

606

607

608 Figure 7. PSD curves of a compacted soils at various densities and constant water content of $21 \%$.

609

610 
612

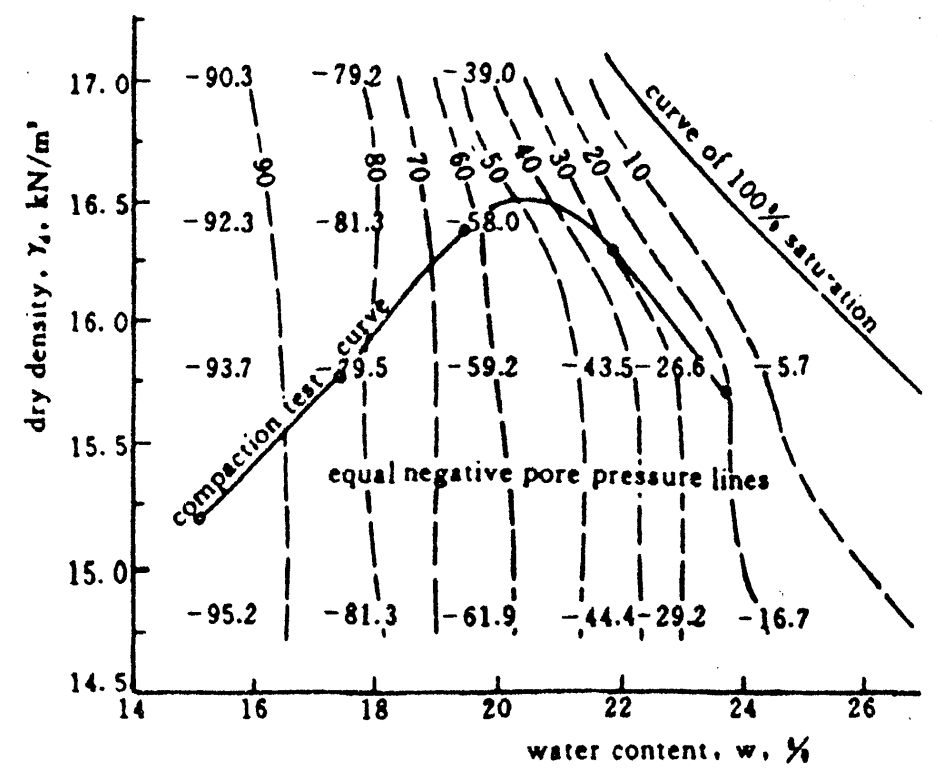

613 Figure 8. Changes in suction with density, at constant water content (Li et al. 1995)

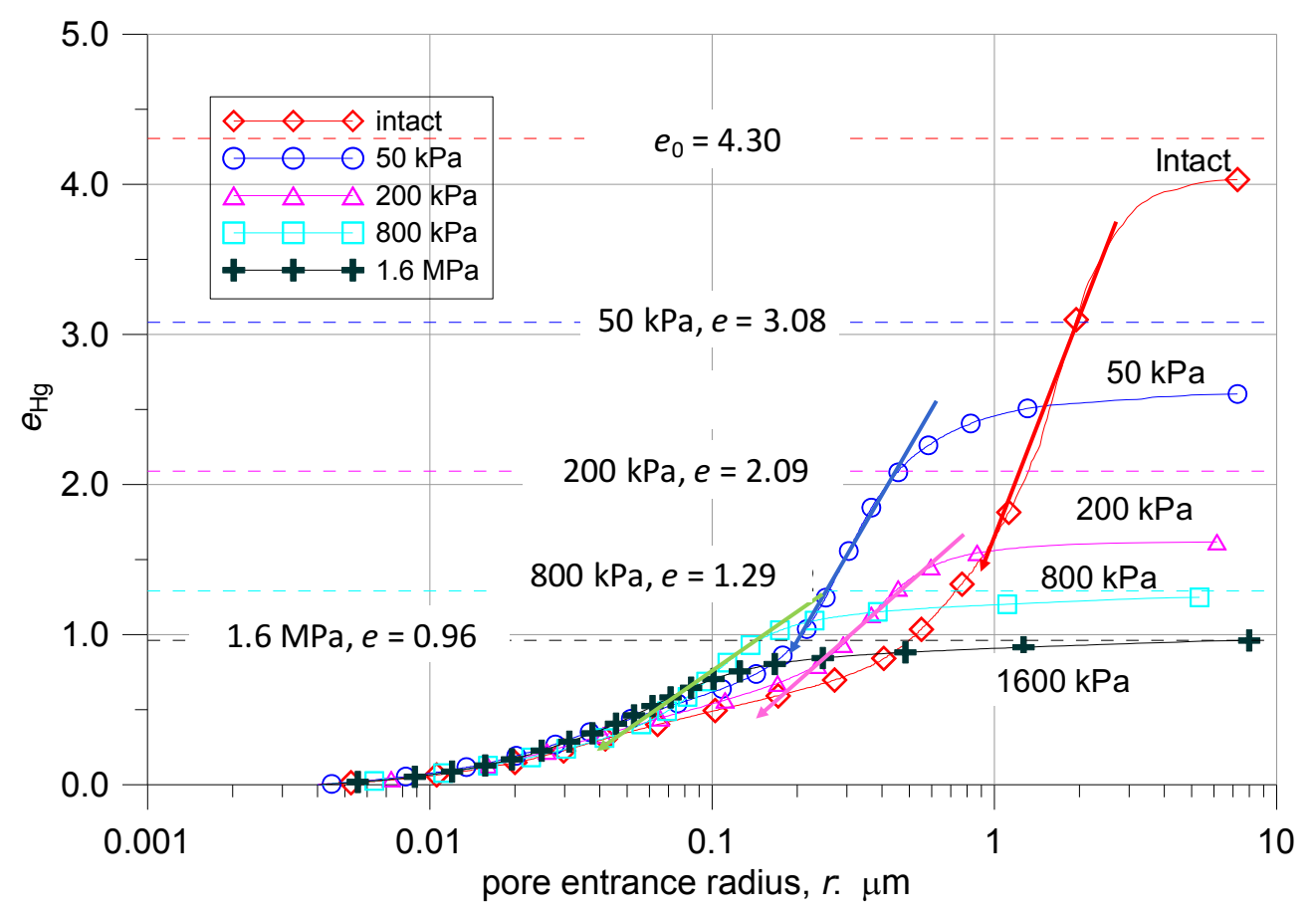

614

615 Figure 9. Changes in pore size distribution curve of a clay from Gulf of Guinea compressed at various vertical 616 stresses in the oedometer (Le at al. 2008). 

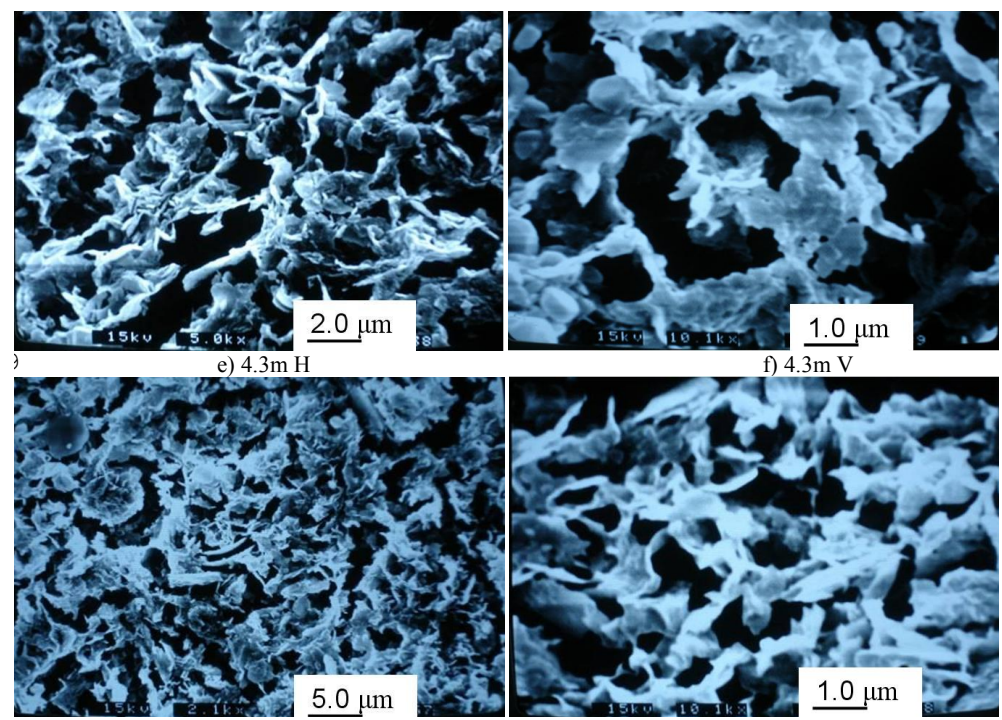

618 Figure 10. SEM photo of a highly plastic clay $\left(I_{p}=100\right)$ from the Gulf of Guinea (Le 2008)

619

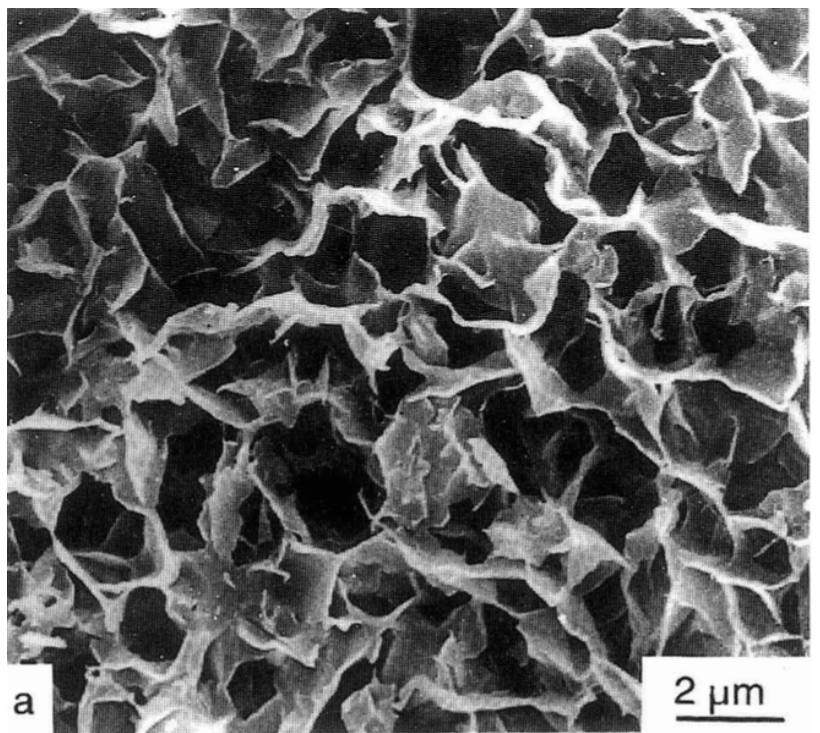

$$
w=369 \%
$$

Suction $3.2 \mathrm{kPa}$

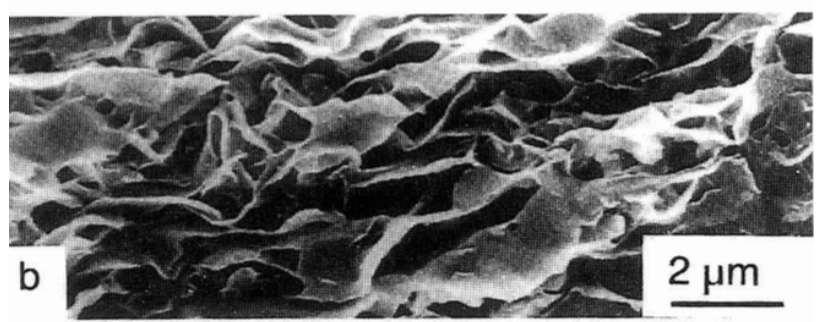

$$
w=114 \%
$$

Suction $100 \mathrm{kPa}$

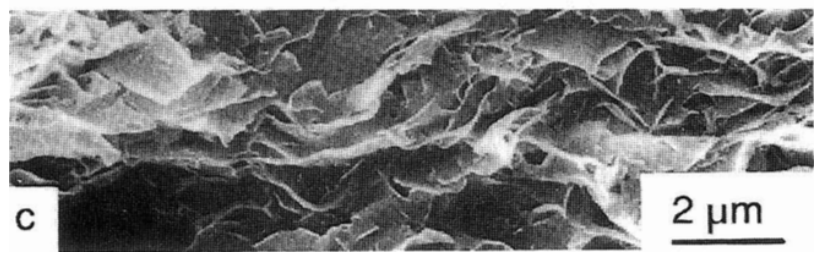

$w=82 \%$

Suction $1 \mathrm{MPa}$ 
621 Figure 11. SEM photos of $\mathrm{Na}^{++}$montmorillonite suspensions submitted to various suctions ( $w=369 \%$ under a 622 suction $s=3.2 \mathrm{kPa}, w=114 \%$ under $s=100 \mathrm{kPa}$ and $w=82 \%$ under $\mathrm{s}=1 \mathrm{MPa})($ Tessier 1991).

623

624

625

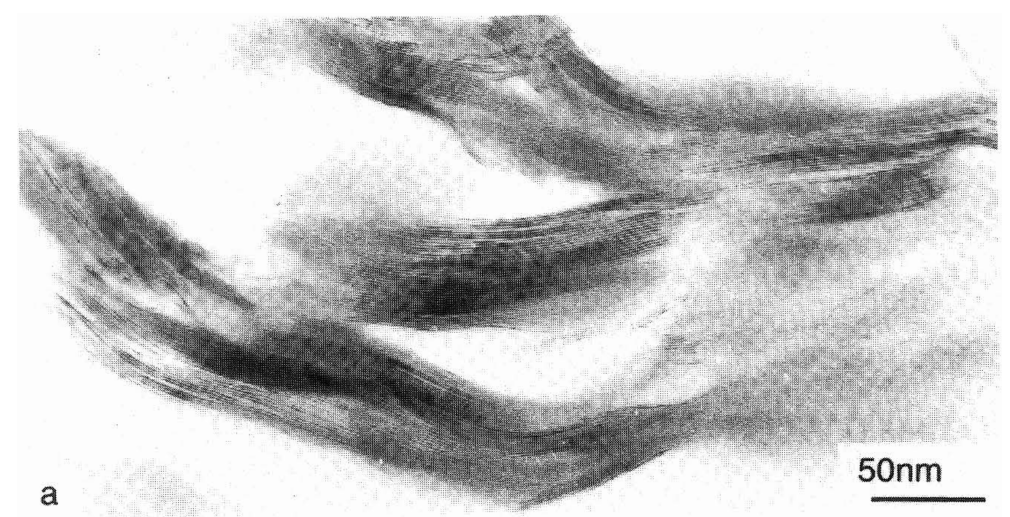

626 Figure 12. TEM photo of the wall of montmorillonite suspension (Tessier 1991).

627

628
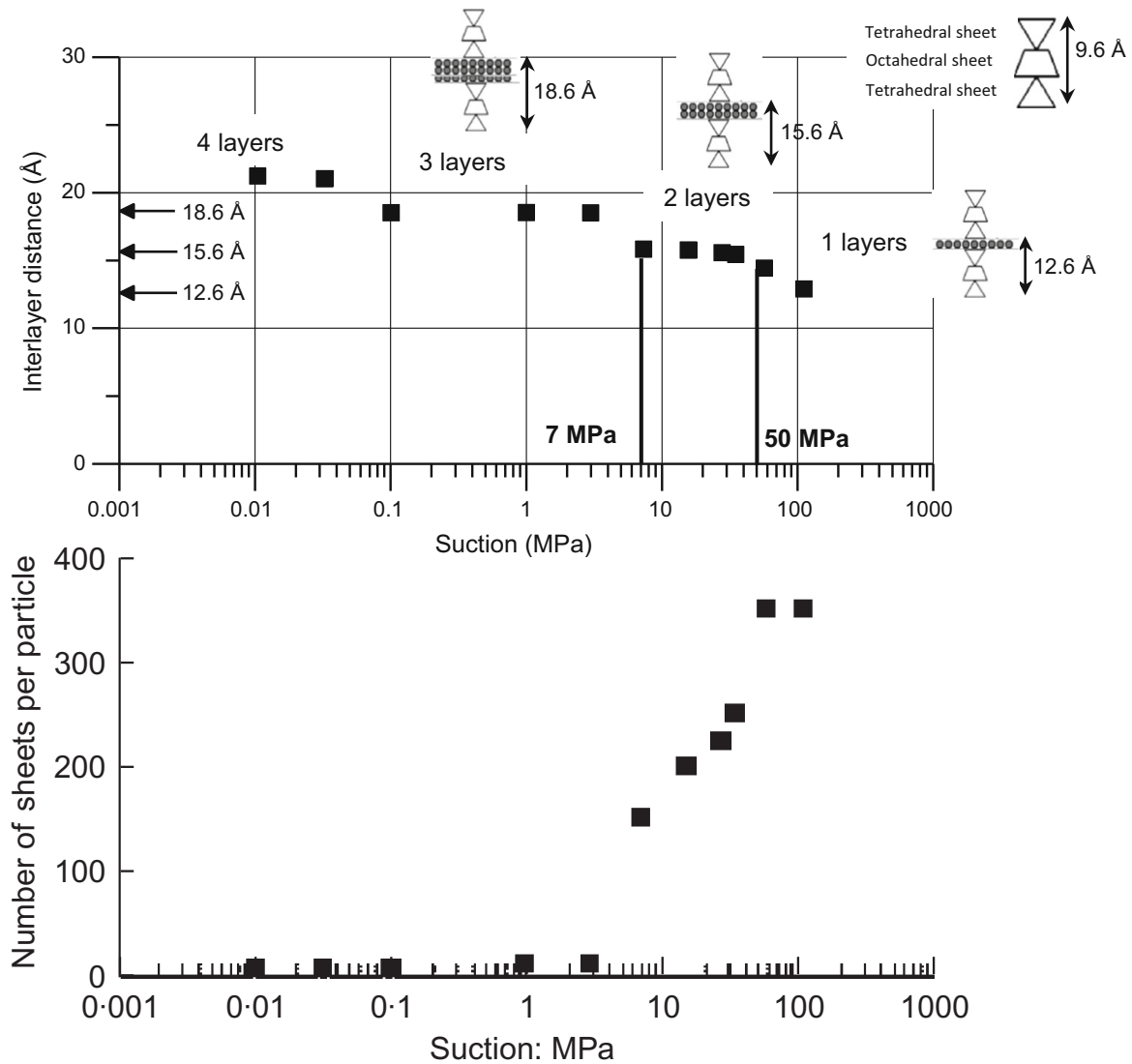

Figure 13. Hydration mechanisms in a compacted MX80 bentonite (after Saiyouri et al. 2004). 


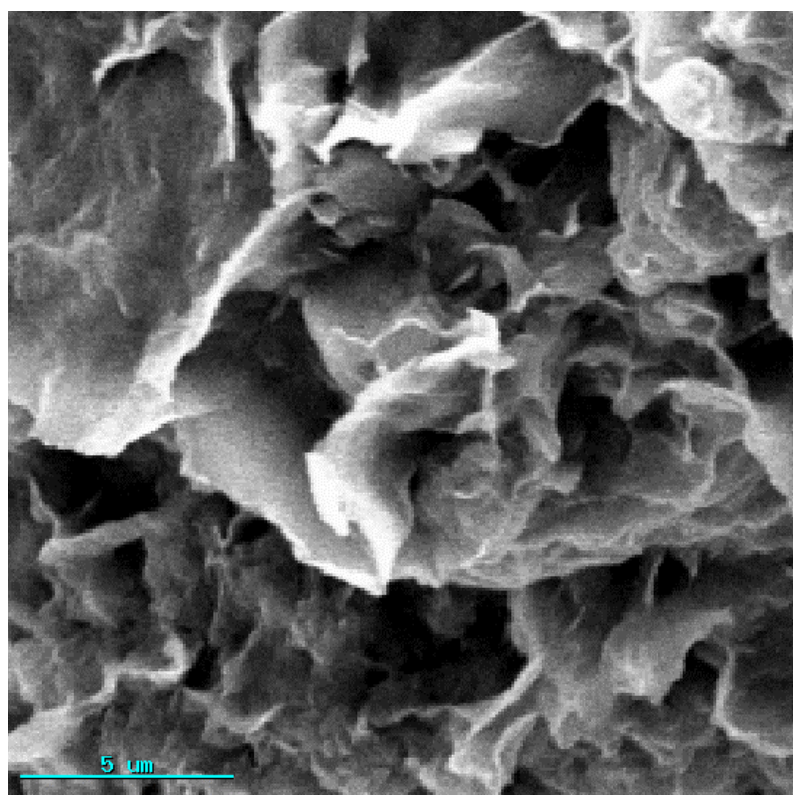

632 Figure 14. Fully hydrated and swollen Kunigel compacted bentonite (Cui et al. 2002).

\section{3}

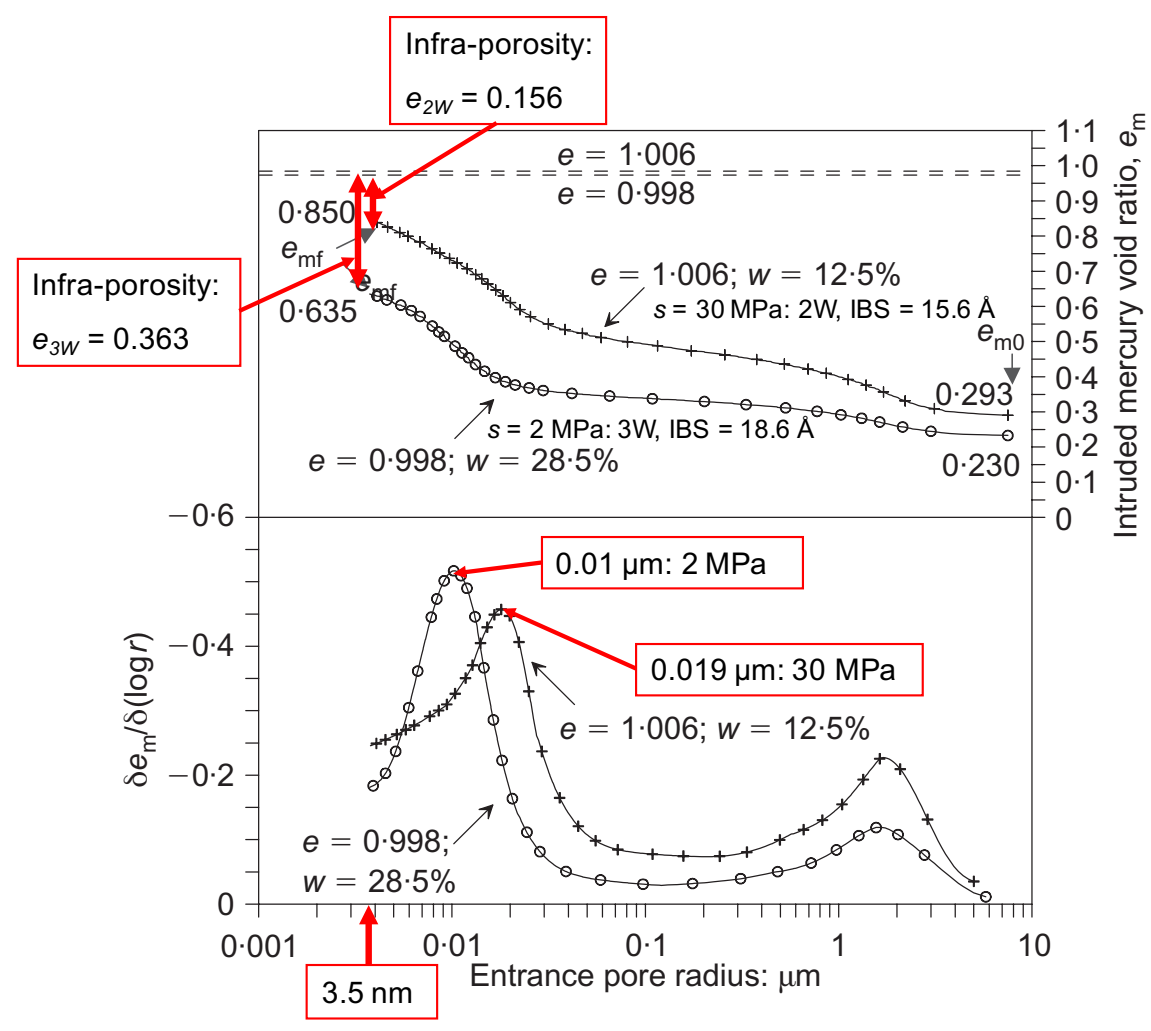

635 Figure 15. PSD curves of MX80 compacted samples at same density and different water contents (After Delage 636 et al. 2006). 


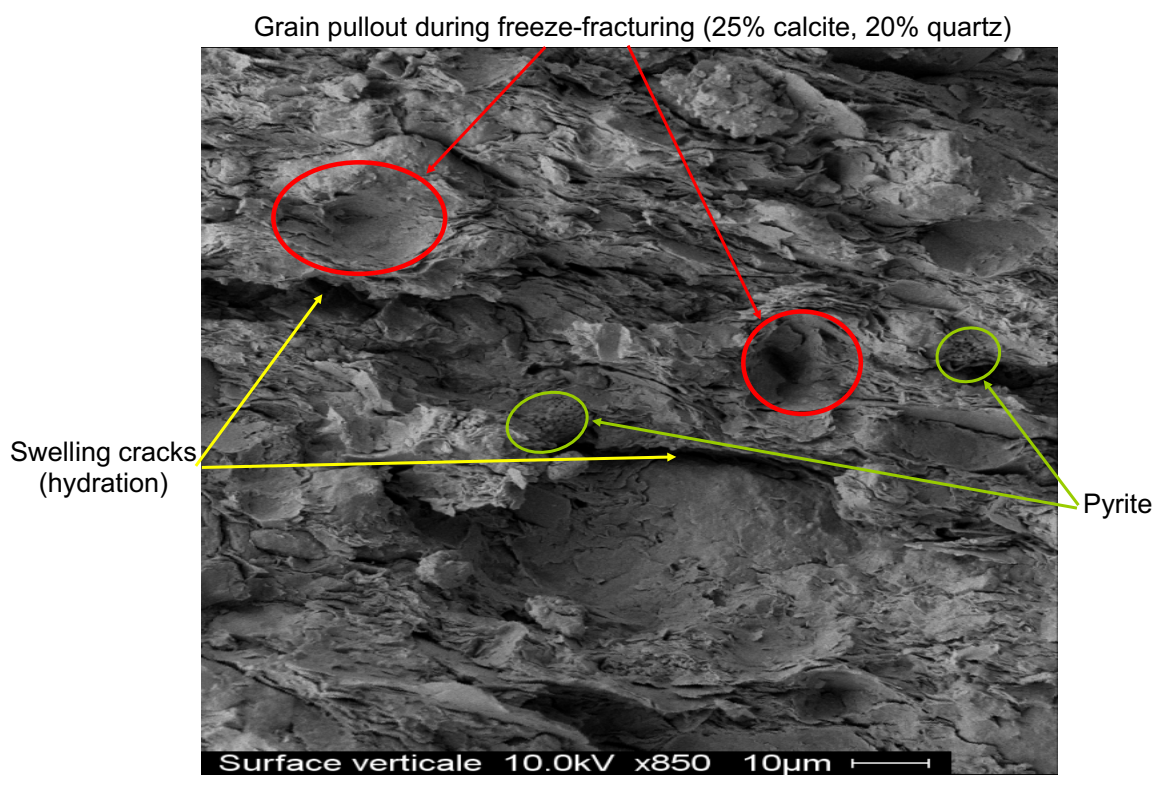

639

Figure 16. SEM observation of a freeze-fractured plane of the Callovo-Oxfordian claystone (Menaceur 2014).
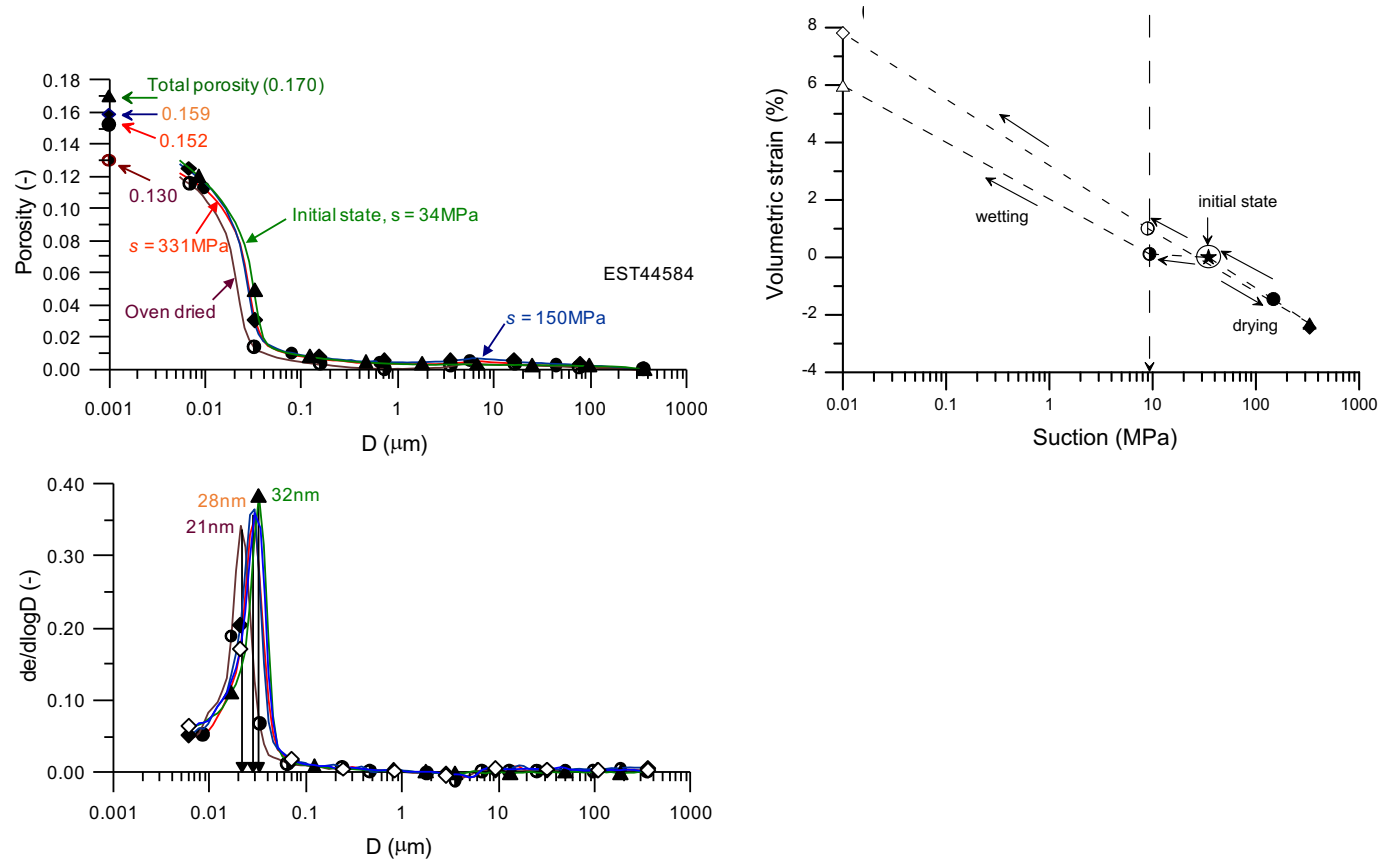

641

642 Figure 17. PSD curves of COx claystones specimen from initial state along a drying path (suctions of 34, 150, 330

643 MPa and dry state), after Menaceur et al. (2016). 


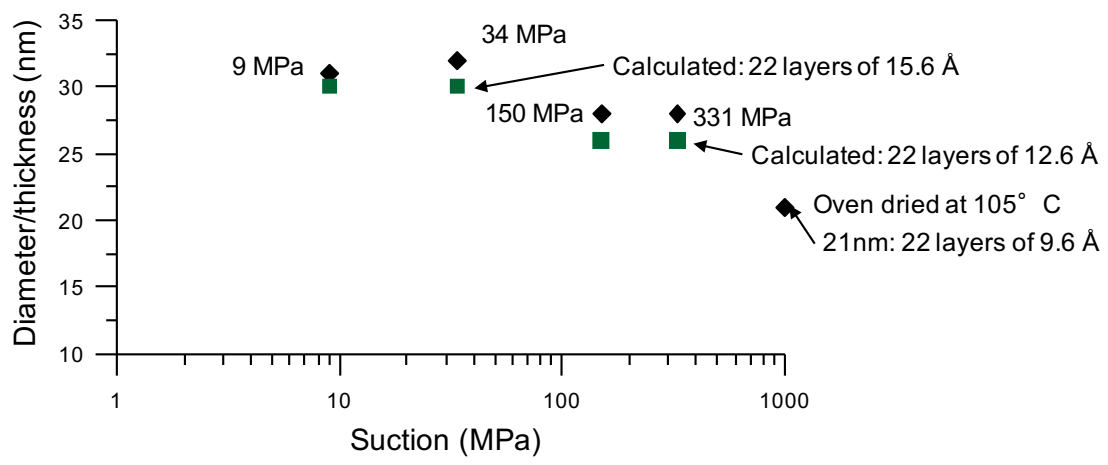

645

646 Figure 18. Measured and calculated platelet thicknesses along the drying path (suctions of 34, 150, 330 MPa

647 and dry state), after Menaceur et al. (2016).

648

649 